\title{
Assessing the Accessibility of Disabled Guests' Facilities for Enhancing Accessible Tourism: Case Study of Five- Star Hotels' Websites in Alexandria Noha Ibrahim Khalil ${ }^{1} \quad$ Eslam Ahmed Fathy ${ }^{2}$ \\ ${ }^{1}$ High Institute of Tourism, Hotels and Restoration- Abukir \\ ${ }^{2}$ Faculty of Tourism and Hotel Management - Pharos University
}

\begin{abstract}
The World Tourism Day 2016 was about accessible tourism "Tourism for All - promoting universal accessibility. The aim of the paper is to improve the accessibility of disabled guests' facilities on hotels' websites in order to maximize Alexandria's share of international disabled tourist market. The study developed an assessment criteria template of hotels websites accessibility for disabled guests. The methodology of content analysis was used in order to assess the accessibility of potential disabled guest's facilities of five- star hotels websites in Alexandria according to the template. The results indicated that the hotels' websites, according to various impairments, are not fully accessible, so that the hotel operations and the destination could lose a promising share of tourist market. In order to enable disabled people to equitable access to their hotel facilities, the current study recommended using assistive technologies and varied display methods on hotels websites' for making information about disabled guests' facilities more accessible.
\end{abstract}

Keywords: accessible tourism, disability facilities, assessment criteria, WCAG2.0, content analysis.

\section{Introduction}

In recent years accessible destinations are more likely to be chosen by People with Disabilities (PWD) (Visitbritain, 2016). However the segment of disabled travelers is a promising segment of international tourist market, tourism and disability is scarcely examined in tourist studies (Navarro, Garzon and Tierno, 2015). The mission is not only about providing these distinctive segment adequate services and facilities but also the availability and accessibility of reliable information about tourism facilities and hospitality operations. The current study is about assessing five-star hotels' website in Alexandria as an Egyptian destination with great potentials for disabled tourist market and its effect on disabled guest intention to use the hotel facilities. Theoretically the current study is considered as a serious scientific attempt to shed light on the concept of accessible tourism and the mechanisms of its implementation, especially with regard to accessibility of information on hotels' websites. On the practical side, the study developed an assessment criteria template of hotels websites accessibility for disabled guests, so that hotels' managers can evaluate theirs according to those criteria. The study begins with a literature review, research methods, then the results are illustrated and discussed and finally, the conclusion and recommendations are presented giving hotel managers some insights in the particular circumstances of the case.

\section{Literature Review}

\section{Disability, accessibility and Tourism}

A billion persons and more allover the world have a disability representing $15 \%$ of world habitants (World Health Organization, 2011). This number will be constantly increasing and the percentage of disability is about $30 \%$ if it includes pregnant women, elderly people, and families with young children and the others who have temporary disability (Vila, Darcy and Gonzalez, 2015). In 2003 the European Agency for Safety and Health At Work, indicated to the term, 
People With Disabilities (PWD), as the individuals with physical, sensorial and mental impairments (Navarro, Andreu and cervera, 2014). According to Bizjack 2011 the tourist market of disabled is worth about 117 billion USD per year (Allan, 2013).

The World Tourism Day 2016 was about accessible tourism "Tourism for All - promoting universal accessibility" (UNWTO, 2016). Buhalis and Darcy (2010) mentioned that Accessible tourism is about enabling disabled people to equitable access to universally designed tourism products, services and environments (Loi and Kong, 2015). Universal Accessibility would be greatly enhanced by widening tourism services delivery, For instance, accessible accommodation that adequately meets the needs of disabled guest's facilities is considered as a determinant or a constraint of travel and tourism. (Darcy and pegg 2011).

Darcy (1998) stated that availability of information on accessible destinations plays a vital role in increasing tourism opportunities for disabled potential tourists (pagan, 2012). Because of the importance of the informational need as an enabler of travel, the disabled tourist looks for the crucial five components of informational needs ; richness and reliability of information, appropriate travel information sources, communication and customer oriented services (Eichhorn, Miller, Gra ham, Buhalis, ,2008).

consequently, if the obstacles about hotel accommodation may inhibit travel as stated by McKercher, Packer, Yau , Lam (2003), the accessibility of hotel services and the availability and veracity of related information is a major step for decision making of hotel accommodation and tourist destination choice (McKercher, Packer, Yau, Lam, 2003). Darcy 2010 also added that detailed information provision using some format like textual, floor plan and digital photography has benefits for accommodation information accessibility (Darcy, 2010). According to UNWTO 2013, People with Disabilities (PWD) need a reasonable adjusted and appropriate accommodation in a universal design which means a design of products, and services without the need for adaptation or specialized design. Also, the use of sign language, Braille, guide dogs for blind, Visual alarm systems rooms for deaf hotel guests, measures and routes to emergency exits should be ready for the disabled (UNWTO, 2013).

\section{Barriers of the accessibility of hotel facilities for disabled guests}

People with disabilities (PWD) don't only suffer from the discrimination that deprives them from social participation in travel and tourism, but also the unsuitable design that prevents access to goods and services which reduces their self-determination to travel by themselves (Michopoulouet.al, 2015). So that travel decision is more difficult to make for the disabled tourist than for other tourists (Blichfeldt and Nicolaisen 2010).

Therefore, the accessibility of environment is considered a reason for not feeling the social exclusion which is considered the main barrier of travel (Wazzan, 2015). Consequently, experiencing positive emotions and overcoming weakness and apathy are very important motives for tourism for the disabled potential tourists (popiel, 2016).

According to McKercher, Packer, Yau, Lam (2003), there are intrinsic, economic, environmental, and interactive constraints for participating in tourism activities (Hua, Ibrahim and Chiu, 2013). McKercher, Packer, Yau, Lam (2003) and Opening Doors (2002) found that lack of knowledge is one of the major barriers for disabled guests (Grady and Ohlin 2009). Smith (1987) indicated to the interactive constraints that relates to unavailability and inaccuracy of tourist services information (McKercher, Packer, Yau, Lam. 2003) it is a form of discrimination, which conflict with the 2016 UNWTO slogan "the tourism accessible for all". In other words, unequaled tourism opportunity between healthy and disabled is shown as a barrier especially 
which is communicational because it strongly affects the people with disabilities especially if it is distorted and unadjusted (Popiel, 2016)

Recently, In February 2017, The American Physical Therapy Association (APTA) had a Combined Sections Meeting (CSM) accessible to all persons. It was for accommodation reservation accessibility for a disability needs (APTA, 2017).

\section{Accessibility and hotels Websites}

Internet and Web technology play a vital role in providing customers the access to millions of tourism facilities of private companies and public sector stakeholders in tourism through accurate and updated information in all of the stages of their journey prior, during and even after the journey (UNWTO, 2016). The website allows delivering information about journy with no need for printing traditional paper-made brochures or advertising materials ( $\mathrm{Li}$ and Wang, 2011).Therefore, many guests make their choice of accommodation also based on upon hotel's website information so that it should be accurate and updated (Grady and Ohlin, 2009).

As mentioned by Grady and Ohlin (2009), the hospitality business should have veracity on website to give customers a realistic expectation of hospitality facilities to avoid litigation (Grady and Ohlin2009). According to Rachman and Buchanan (1999), Successful website is the main factor that attracts users and generate traffic to the website (Kokash, 2012). According to Buhalis (2003) disabled people considers the internet as a primary source of information and a crucial Knowledge base, obtaining easy up-to-date travel information, deliver and exchange information about their accessibility needs to the service provider and plan their trips (Zhang and cole, 2016). In order to provide more detailed information about accessible facilities, it is important to identify the disabled customers' preferences (Loi and Kong 2015). In the shade of increasing maturity of internet users in the last decades, Internet reservation systems necessitate personnel who are responsible for interaction with disabled guests' questions and inquiries,' live chats" and email responses (Grady and Ohlin, 2009)

The assessment of tourism suppliers websites is considered a vital job for updating the website according to the latest attributes and trends, through maximizing strengths and avoidance of weaknesses (Pranić, Praničević and Arnerić, 2014). The tourism and hotels websites assessment criteria were studied with different methodologies and from many perspectives; the consumer perspective, the business function and the integration of both (Gregory, Wang, and DiPietro, 2010).

Rachman and Buchanan's tourism assessment of websites depended on four aspects of usability, interactivity, speed, and presentation that let users repeat the virtual visit (Gregory, Wang, and DiPietro, 2010 and, Kokash, 2012). Gutierrez, Loucopoulos, and Reinsch (2005) recommended that the website should provide voice output with images, videos and texts. They conducted the search on a group of disabled people with a variety of disabilities to assess the web page accessibility or how they can access information efficiently. There are also an evaluation models for tourism destinations websites such as Douglas and Mills evaluation model (2004) within three primary factors: user friendliness, site attractiveness, and marketing efficacy (Gregoryet al., 2010).

The Web Assessment Index (WAI), is another trial to evaluate the quality of a 100 hotels Websites from the 10 top cities destinations in the world, based on 4 dimensions: visibility, speed, navigability, and content (Miranda, Rubio and Chamorro, 2013). An amended modified Balanced Scorecard (mBSC) approach was used to evaluate 197 hotels in Croatia from the userfriendliness, site attractiveness, marketing effectiveness, and in formativeness perspectives 
(Pranic, Pranicevic, and Acrenic, 2014). Above, Gregory, Wang and DiPietro (2010) proposed a conceptual model as a reference for hotel website evaluation and has five components: Information, Communication, Transaction, Relationship and Technical.

The Web Content Accessibility Guidelines (WCAG) 2.0 is testable success criteria for web content; through using them by IT developers in hotels, Web content will be more accessible and easily usable to the people with all types of disabilities, especially for potential guests. WCAG is mainly intended for developing and evaluating web contents including texts, images, and sounds, etc. consequently, this enhances the functionality of the Web as a standard for web accessibility (www.w3.org). Then the hotel websites developers will have a better knowledge about the criteria of the successful websites. So that they will be improving the offered service to potential customers and then increasing their number.

\section{Research Methods}

The study has developed a template form as an instrument of assessment criteria leading to optimally interpretable results. The developed template was derived and adapted from:

1- UNWTO (2016) Recommendations on accessible information in tourism.

2- Gregory, Wang and DiPietro (2010) model.

3- Web Content Accessibility Guidelines (WCAG) 2.0 that is also recommended by UNWTO (2016) Recommendations on accessible information in tourism. The developed template was based on the 4 following main aspects of assessment: website informational content, communication, transaction, technical features.

The template was presented to thirty of people with disability (PWD) in order to ensure that the criteria of assessment of the contents of the websites related to their facilities, are useful according to their type of impairment (ten persons with physical and twenty with sensory, eight are deaf and six are blind and the rest are impaired with low vision). They suggested adding two criteria of assessment in technical features of websites, screen magnifier in assistive technology and voice browser in navigability for low vision and blind persons respectively. Then they all have recognized that this instrument is useful for them and works on the objectives of the study. According to the proposed template, the current study adopted Content analysis method, because of its effectiveness as a qualitative investigation tool of communication content and interactivity in human-computer interaction such as Web-based contents. Therefore, it is proper for complex and rich mixture web site content. Content analysis enables to analyze the unstructured large quantity of data to be structured. In current research, the Content analysis was used to examine how the Alexandria hotels are designing, developing and using their websites as an attracting tool for the potential disabled tourist market. A survey of official sites of the seven five- star hotels in Alexandria was done on January 2017. 
International Journal of Heritage, Tourism and Hospitality Vol. (11), No. (3/2)

Special issue on papers of the $10^{\text {th }}$ ICTH (2017) organized by Faculty of Tourism and Hotels, Fayoum University

Table1: Assessment Criteria Template of Hotels Websites Accessibility for Disabled Guests

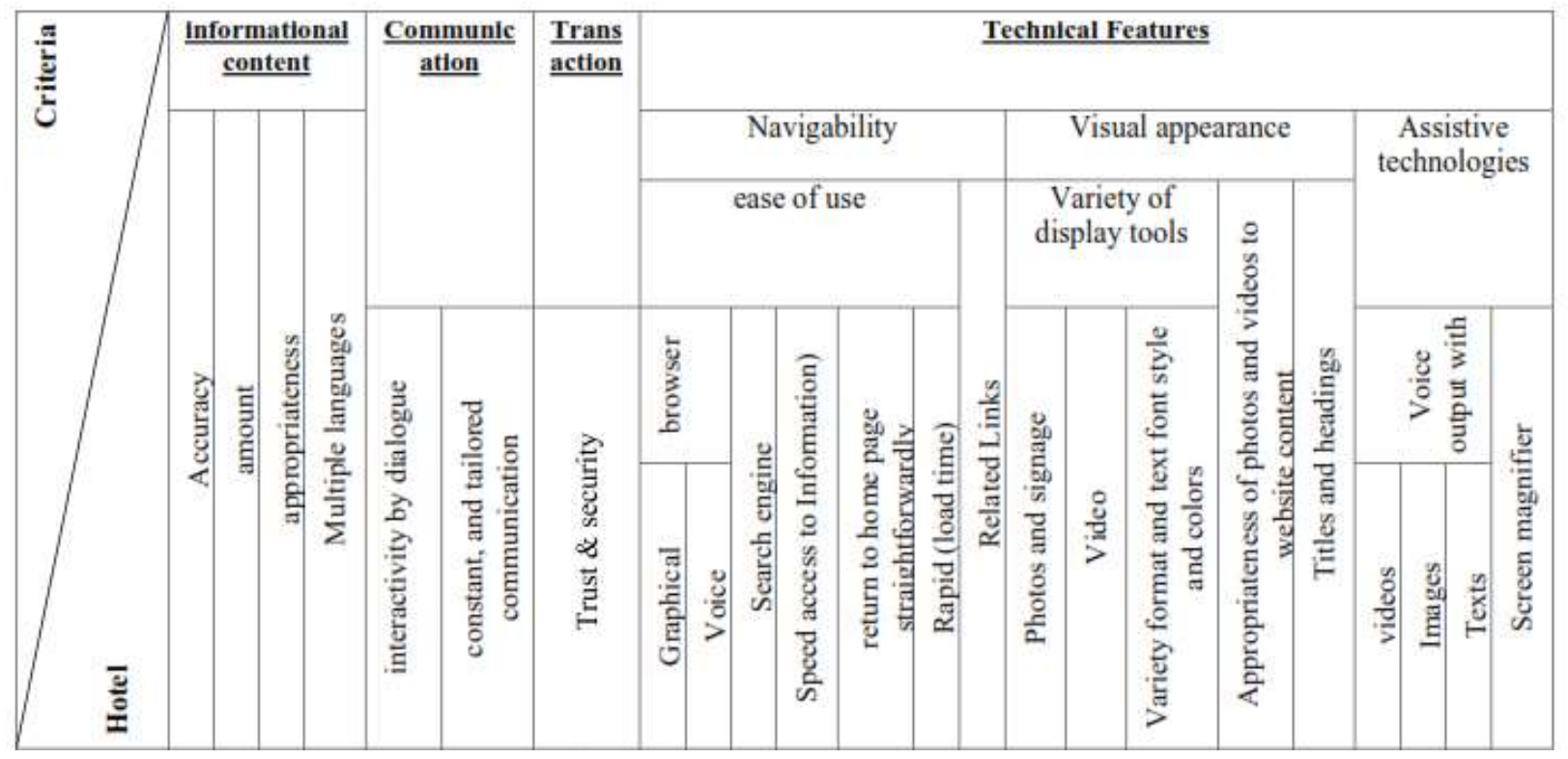

\section{Hypotheses of the study}

H1- The websites of five- hotels in Alexandria are not accessible for disabled guests' facilities according to various impairments.

H2- The websites of five-star hotels in Alexandria don't apply the criteria of successful websites for potential disabled guests.

\section{Results and Discussions}

Firstly, the study counted the sentences related to accessibility in Alexandria five- star hotels websites (Table 2), as a simple quantitative content analysis and it was obvious that hotel (B) is the most accessible one. On the other hand, Hotels (E) and (F) were the least accessible in information related to the disability facilities and hotel $(\mathrm{G})$ hasn't any indication to the disabled guest facilities. These results are supported by Navarro, Andreu and cevera (2014) because web pages of the hotel should include information on accessibility because it makes accommodation choice decision and reservation easier.

Table 2: Counting of sentences related to accessibility in five- star Alexandria hotels websites

\begin{tabular}{|l|l|}
\hline \multicolumn{1}{|c|}{ Alexandria five- star hotels } & \multicolumn{1}{|c|}{ No of sentences related to accessibility } \\
\hline Hotel (A) & 15 \\
\hline Hotel (B) & 21 \\
\hline Hotel (C) & 14 \\
\hline Hotel (D) & 17 \\
\hline Hotel (E) & 1 \\
\hline Hotel (F) & 1 \\
\hline Hotel (G) & N/A \\
\hline
\end{tabular}

Secondly, the content analysis was used in order to assess the accessibility of disabled guest's facilities of five-star hotels websites in Alexandria according to the assessment criteria template (table1) as follows. 


\section{1- Informational content}

\section{1-1 Accuracy}

-Hotel (A) there is detailed and specified information about each accessibility service.

- Hotel (B) There is a non - availability note about some features of accessible room width of entry and passage.

- There's also a wrong indication, the website mentioned that the corresponding photo may not reflect the specific accessible room type or room feature although there is no photo at all. So that accuracy is not fully existed.

-Hotel(C) there is a hotel details section contains available and non- available services, one of them is Accessible room. There are no specific rooms for disabled but only disability facilities in the rooms.

-Hotel (D) There is a measurement of the door width in the accessible rooms.

Hotel (E) There is a difference between the Arabic and English version in specified information about service in the accessible rooms. For Hotel $(\mathrm{F})$ information is only appropriate for physical impairments guests "wheelchair-accessible rooms". According to Zhang and Cole 2016, Accurate and detailed information is crucial for information credibility.

1-2 Amount of Information

Hotel (A): The website contains many accessibility services as follows

- For physical impairment Bathroom and bed room's measurements, Swimming pool hoist for pool access and Wheelchair ramp for lobby and reception access. Evacuation chair, Level or ramp entrance into the building, Lowered light switches, Public Areas and Facilities accessible for physically challenged, Rooms accessible to wheelchairs.

- For sensory impairment Digital alarm clock available with sound and strobe light, Audible alerts in elevators, Service support animals welcome.

- For all types of impairments Accessible Rooms, Accessible elevators, Accessible meeting rooms, Emergency Call Button on Phone. Accessible Room amenities list is mentioned also.

Hotel (B): the website contains many accessibility services as follows:

- For physical impairment grab bars in bathroom Level or ramp entrance into the building, Public Areas/Facilities accessible for physically challenged, Rooms accessible to wheelchairs, Wheelchair ramp for lobby/reception access, Bathroom doors at least 32 inches wide, Bedroom doors at least 32 inches wide $(812 \mathrm{~mm})$.

- For sensory impairment Visual alarms for hearing impaired in hallways and in public areas, Alarms - Audible Digital alarm clock available with sound and a vibrating pad, Large Print Menus for blind guests, Service support animals welcome,Strobe alarms.

- For all types of impairments Accessible parking, Accessible elevators, Accessible meeting rooms, Emergency Call Button on Phone.

Hotel (C): the website contains many accessibility services as follows:

- For physical impairment Bathroom and bed rooms measurements, Cutlery with oversized or adapted handles, Evacuation chair available to help evacuate a disabled person, Level or ramp entrance into the building, Public Areas/Facilities accessible for physically challenged, Rooms accessible to wheelchairs (no steps), Wheelchair ramp for lobby/reception access

- For sensory impairment Digital alarm clock available with sound and strobe light Large Print Menus 
- For all types of impairments Accessible elevators, meeting room, parking, Emergency Call Button on Phone.

Hotel (D): the website contains many accessibility services mainly:

- For physical impairment guest room restaurant meeting room/ballroom fitness center swimming pool business center. But only one service is for hearing impairment

Hotel (E): only on Arabic version of the website homepage there is one phrase indicating that there are services for disabled guests, after clicking on "service button". And they mentioned that "When clicking on the rooms button there is an image entitled "accessibility features" indicating to their rooms " our Alexandria hotel offers a selection of rooms with special accessible options"

- Only on the English version, But not on the Arabic, there is a statement under the title of "rooms": "We also offer accessible rooms to ensure all guests enjoy a comfortable stay in Alexandria."

- When clicking on an image illustrating a room, there is a signage nearby a statement: "Our Alexandria hotel offers a selection of rooms with special accessible options". The signage is illustrating the physical impairment

Hotel (F): when clicking the button "accommodation" there is a title of "for family and special needs".

\section{1-3- Appropriateness}

Hotel (A)

- The accessibility information is appropriate to all impairments but there is a great attention to the mobility impairment because there are 9 of 16 services related to this type of impairment.

- There are 3 accessible services for sensory impairment either for deaf or for blind guests depending on sounds and lights.

- The rest is appropriate to all types of impairments either related with rooms, meeting rooms, elevators and emergency call system.

- the website repeated the word" accessible" 6 times, access: 2 times, disabled and physically challenged: once a time. These repeated words indicate the website great attention to the disabled guests' needs.

- The corresponding photo to the accessible room's features may not reflect such room.

Hotel (B)

-The accessibility information is appropriate to all impairments but there is a great attention to the mobility impairment because there are 8 of 20 services is related to this type of impairment.

-There are 7 accessible services for hearing impairment depending on lights and 4 for blind guests depending on sound.

-The rest is appropriate to all types of impairments either related with rooms, meeting rooms, elevators, parking and emergency call system.

-the website repeated the word" accessible" five times, physically challenged: once a time. Hearing impaired: 3 times, these repeated words indicate the website great attention to the disabled guests' needs.

-There is no corresponding photo to the accessible room's features.

-The features of accessible room are not related to the disability needs except for the room measurements. The stress was on the additional space and amenities that physical impaired guests need either for this hotel accessible room or for the hotel (A). 
Hotel (C)

The accessibility information is appropriate to all impairments but there is a great attention to the mobility impairment because there are 8 of 14 services is related to this type of impairment.

- $\quad$ There are 2 accessible services for blind guests and only one for deaf.

- The website repeated the word" accessible" 7 times, access: 2 times, disabled and physically challenged: once a time. Wheelchair 2 times, these repeated words indicate the website great attention to the disabled guests' needs.

- No separated section for the accessible rooms on the website.

- Hotel (D) The accessibility information is appropriate to all disabled and non-disabled guests but there is a great attention to the mobility impairment because all services are related to this type of impairment.

- There is only one of accessible room services for hearing impairment that is "Visual fire alarm" and the rest is for mobility impairment.

- The website repeated the word" accessible" 7 times with mobility disability services, access- mobility - accessible: once a time. These repeated words indicate the website great attention to the mobility disabled guests' needs.

- Hotel (E) the accessibility features image hasn't any relation to impairments.

- Hotel (F) Information is appropriate to physically challenged impaired guests because it indicated to wheel-chairs rooms.

\section{1-4. Multiple Languages}

All websites have 2 languages for displaying the informational content except for Hotel (D) that has 9 languages.

\section{2- Communication}

\section{2-1 Interactivity by dialogue}

For hotels (A), (B) and (C) There is a "customer support" button on the home page contains ability for live dialogues through varied options. Talk to us now, chat now (with a significant signage), talk by computer, push to talk, call us.

For Hotel (D) there is a blog for accessibility needs

http://knowledge.usablenet.com/h/c/218322-web-

accessibility?_ga=1.78501916.981511178.1485680550

And there is a review button for all websites. For (E) there is find us on section

And For $(F)$ there is Social Live section. These sections are for social media pages and there is also an application of the chain.

\section{2-2 Constant and Tailored communication}

For hotels (A, B, and C) there is a "contact us" button, e-mail us, give us your phone number and we will call you and there is a button of "feed back" for customer care issues and for recent stay feedback please, and also for rating experience on the site by adding images for describing emotions of love, like, neutral, dislike and hate.

Hotel D

- Questions about the accessible facilities and services offered are directed to the hotel at a specific phone number.

- There's a feedback button in the page of guest review. 
- There's a "contact us" button on home page and "contact us" "email us" and "speak with us" on existing reservation page when clicking on the button of my reservation on home page. On this page there's a hyper link of "customer care".

- There is chain mobile apps on home page "Mobile Options" as a connection tool.

For hotel (E) there is a "contact us" button, e-mail us. And media accommodation request and best online rate guarantee and review button. For $(\mathbf{F})$ there is a "contact us" request a folio" a customer profile, there's also "sign in "and "e- mail" and there's an app of the hotel chain.

\section{3- Transaction}

\section{3-1 Trust and Security}

For hotels (A), (B), (C) payment information is available for reservation.

There's a global privacy statement for all this hotel chain protects all guest information and organizes the relationship between hotel and guest.

Hotel (D) there are global website Terms and Conditions for Use of it and the chain online privacy statement. Payment information is available for reservation and cancellations page. For (E) there is site usage agreement and privacy policy. There's also privacy policy and legal notes for Hotel (F).

\section{4-Technical Features}

\section{4-1.Navigability}

\subsubsection{Ease of use}

4.1.1.1 Graphic and voice browser No Graphic and voice browser for all websites.

\subsubsection{Search engine}

Search engine for all websites is for reservation and it's available only for non - disabled potential guests

\subsubsection{Speed access to information}

There was an easy access to the accessibility facilities with one click on "Amenities and services for Hotel (A) and also one click on " accommodation button" for Hotel (F) Although there was a difficulty in accessibility for the accessible rooms in hotel (B) and hotel (C). For Hotel (D) there was an easy access to the accessibility facilities with one click on "rooms "and to the accessible rooms with 1 click. For Hotel (F) And Hotel (E) there was an easy access to the accessibility information.

4.1.1.4 Return to Home page straightforwardly there was an easy return to the homepage in all websites.

4.1.1.5 Rapid load times: For all websites there is a rapid navigation through the website.

\subsubsection{Related links}

There are related links

(A), (B), (C) And (D) have the hotel chain website

For all websites trip advisor booking.com and for hotel (C)

The same related links of the previous hotels and there is also other important links: http://www.hospitalityonline.com/employers/234366

https://ar.hotels.com 


\subsection{Visual Appearance}

4.2.1 Variety of display tools for (A) a (B) (C) and (E) and (f) there is an only signage indicating to the Accessible Room illustrating a person on wheelchair that means a concentration on the physical impairment.

\subsubsection{Photos Videos and signage}

The signage and photos are available but not sufficient for effective display of disability facilities except for physical impaired guests. And no videos at all in all websites for disability facilities

\subsubsection{Variety format and text font style and colors}

(A) (B) and (c) no variety in font style but in font size and No color contrast, some people cannot read text successfully if there is not sufficient contrast.

For Hotel (D) there is a variety in font style and font size and there is a color contrast between blue, grey and black in accessibility services. There are text and non- text -mode of the site and Assistive Options but not applied. When clicking on "usablenet", appeared Accessibility Services.

Hotel (E) no variety in font style or in font size and there is color contrast between black and blue.

Hotel (F) no variety in font style or in font size and there is color contrast between black and blue

\subsubsection{Appropriateness of photos and videos to website content}

The signage and photos are appropriate for effective display of disability facilities for all websites.

4.2.1.4 Titles and Headings, for hotels (A) (B) and (C)

No headings classifying the impairments accessible facilities and there was an only one a page title shown in the window title bar "accessible" indicating to accessible room.

According to Website Content Accessibility Guidelines, Good page titles are very impressive for orientation and help people know where they are and move between pages open in their browser. The first thing screen readers say when the user goes to a different web page is the page title

For hotel (B) hearing impairment was mentioned in 3 statement in the accessibility facilities, "physically challenged" once a time but there is no clear mentioning to the seeing impairment although there are related facilities.

For Hotel (D) there is 2 classifying headings differentiating accessible guest rooms and accessible public spaces under a great title of " accessibility".

-There is a page title shown in the window title bar indicating to accessibility http://usablenet.com/products/web-accessibility and for more information click appeared web accessibility with texts and images about navigation for disabled

http://knowledge.usablenet.com/h/c/218322-webaccessibility? ga $=1.78501916 .981511178 .1485680550$

For hotels (E) and (f) no headings and titles

\subsection{Assistive technology}

Assistive technology for the disabled potential guests is not existed at all websites except for (D)'s but it's not applied. 


\section{Summary}

The findings outlined in this research as follows:

- It is noted that the A, B, and C hotels have relatively richness in the amount and variety of the disability information about physical and sensory impairments.

- Obviously, for all websites there's more accessibility for information about physically challenged potential guests' facilities in comparison to the other impairments.

- All websites are updated.

- For hotels (A), (B), (C) and (D), the adoption of WCAG 2.0 standards is a first step for the website accessibility for the potential disabled guests.

- The hotels' websites content analysis indicated that websites have not efficient information about disabilities facilities according to various impairments, so that the websites are not fully accessible. This means that the first hypothesis is accepted.

- The current study concluded that most hotels' websites are not addressing the assistive technologies, and diversity of information, and variety of display methods, appropriate navigability browser, thereby the websites are ignoring a significant proportion of the potential tourists' market. So that, the second hypothesis is also accepted.

\section{Conclusion and Recommendations}

Although this paper is relatively small in scale, it highlights the concept of accessibility as a critical issue within tourism research, recognizing that disabled tourists should have the same opportunities for tourism services as others. It emphasizes the need of providing accessible information about their facilities on hotels websites. The current study concluded that most hotels' websites have information about disabilities facilities, but it does not mean that it is accessible for disabled guests. The conclusions and recommendations of this study are designed to maximize the disabled tourists market in Alexandria, by increasing the website effectiveness to give the hotel a competitive advantage and a positive image among the disabled guests, and their families. In other words the guests with disabilities will choose the hotel if its website provides detailed and effective information displayed in varied methods. The recommendations will help hotel operations to improve their websites for accessibility of disability facilities. So, The Egyptian hotel association should develop policies and rules to meet Web Content Accessibility Guidelines (WCAG) 2.0 in developing theirs. Diversity of information on the hotels' Websites of all the services and facilities is crucial in order to meet the various needs of the impaired guests, such as the deaf and the blind. In addition, structuring the information of web sites with titles and headings according to each type of impairment is needed. Above all, displaying the information in different methods to be accessible by applying the assistive technologies should be as follows; the information of hearing impairment facilities must be appropriately shown in text and non-text such as video; and for blind guest, the texts can be displayed in the form of voice in order to be beneficial to those guests. Voice recognition software (screen readers) with text is vital to help the blind guests to read textual information through synthesized speech or Braille displays. Screen magnifier which enlarges and changes colors on the screen and improves the visual readability of condensed text and image is important for the low vision guests. Hotel websites should also improve the navigability browser by providing mechanisms such as graphical browser and voice browser.

It should be indicated that this was purely an exploratory study, and due to its small sample size, it has obvious limitations. Hotels websites are updated on a regular basis and the analysis may be 
changed with each website adjustment. Therefore, the current research that was conducted in January 2017 has checked the last update of websites. Future research should develop a Likert scale for guest perception surveys derived from the template developed by current research that included assessment criteria (Informational contents, transaction, communication, technical features) and their respective items. In order to attract the disabled tourists' markets, related future research should investigate the disability facilities on website of other sectors of the hospitality and tourism including airlines, cruises, restaurants, archaeological, and heritage sites.

\section{References}

Allan, Mamoon (2013) "Disability Tourism: Why does Disabled People Engaging in Tourism Activities?" European Journal of Social Sciences - Volume 39 Issue 3, PP. 480-486.

Darcy, Simon and Pegg, Shane (2011) " Towards Strategic Intent: Perceptions of disability service provision amongst hotel accommodation manager", https://opus.lib.uts.edu.au/bitstream/10453/17439/1/2010004164.pdf / (Accessed: 4/5/2017).

Darcy, Simon (2010) "Inherent complexity: Disability, accessible tourism and accommodation information preferences", Tourism Management, Volume 31, Issue 6, PP.816-826.

Eichhorn, Victoria, Miller, Graham, Michopoulou, Eleni and Buhalis, Dimitrios, (2008) "Enabling disabled tourists? Accessibility Tourism Information Schemes", Annals of Tourism Research, 35 , No.1, PP. 189-210.

Grady, John, and Ohlin, Jain (2009), "Equal access to hospitality services for guests with mobility impairments under the Americans with Disabilities Act: implications for the hospitality industry", International Journal of Hospitality Management, Vol.28, PP.161-169.

Gregory, A., Wang, Y. R., and DiPietro, R. B. (2010) "Towards a functional model of website evaluation: a case study of casual dining restaurants", Worldwide Hospitality and Tourism Themes, Vol. 2, No (1), PP.68-85.

Hua, Khor, Ibrahim, Irini and Chiu, Lim (2013) "Sport Tourism: Physically-Disabled Sport Tourists' Orientation" Procedia - Social and Behavioral Sciences, Volume 91, No.10, PP. 257-269.

Kokash, Husam (2012) "Jordanian Travel Agencies' Websites Assessment: Experts vs. Tourists' Perceptions", International Journal of Marketing Studies, Vol. 4, No 2. PP.80-92.

$\mathrm{Li}, \mathrm{Xu}$ and Wang, Youcheng (2011) " Is Your Official State Tourism Website Effective? A Functional Perspective", scholarworks.umass.edu / (Accessed: 4/11/2016).

Loi, Kim and Kong, Weng (2015) People With Disabilities (PWD) In The Tourism Industry Concepts And Issues, Critical Tourism Studies Conference VI "10 years CTS: Reflections on the road less travelled and the journey ahead", Opatija, Croatia, 26-30 June 2015.

McKercher, Bob, Packer, Tanya, Yau, Matthew and Lam, Patrick (2003) "Travel agents as facilitators or inhibitors of travel: perceptions of people with disabilities", Tourism Management, Vol. 24, Issue.4, PP.465-474.

Michopoulou, Eleni, Darcy, Simon, Ambrose, Ivor and Buhalis, Dimitros (2015) "Accessible tourism futures: the world we dream to live in and the opportunities we hope to have", Journal of Tourism Futures, Vol. 1 Issue: 3, PP.179-188.

Miranda, Francisco, Rubio, Sergio and Chamorro, Antonio (2015) "The Web as a Marketing Tool in the Spanish Foodservice Industry: Evaluating the Websites of Spain's Top Restaurants", Journal of Foodservice Business Research, Volume 18, Issue 2, PP. 146-162.

Navarro Susana, Garzón Dolores and "Tierno Norat Roig, (2015)" Co-creation in hotel-disable customer interactions", Journal of Business Research, Vol. 68 , issue 7, , PP.1630-1634. 
Navarro, Susana, Andreu, Luisa and Cervera, Amparo (2014) "Value co-creation among hotels and disabled customers: An exploratory study", Journal of business research, Vol. 67, PP.813-818.

Nicolaisen , Jaqueline and Blichfeldt, Bodil (2011) "Disabled travel: not easy, but doable", Current Issues in Tourism, Volume 14, Issue 1, pp. 79-102.

Pagan, Ricardo (2015) "Time Allocation In Tourism .For People With Disabilities" Annals Of Tourism Research, Vol. 39, No. 3, PP. 1514-1537

Popiel, Marcin (2016)"tourism market, disability and inequality: problems and solutions", aak.cms.opf.slu.cz/pdf/2016/3/Popiel.pdf/ (accessed: 13/1/2017)

Pranić, Ljudevit, Praničević, Daniela and Arnerić, Josip (2014) "Hotel Website Performance: Evidence from a Transition Country", Tourism and Hospitality Management, Vol. 20, No. 1, PP. 45-60.

Republic of South Africa, Department of Tourism, "Universal accessibility in tourism", https://www.tourism.gov.za/CurrentProjects/ResponsibleTourism/Responsible\%20Tourism/UA \%20brochureL\%202.pdf/ (accessed: 13/6/2017).

The American Physical Therapy Association (APTA) (2017): "Combined Sections Meeting , https://www.apta.org/ (Accessed: 4/11/2016).

UNWTO (2013) "Recommendations on accessible tourism for all: http://ethics.unwto.org/en/content/accessible-tourism/ (Accessed: 4/11/2016).

UNWTO (2016a) "Recommendations on accessible information in tourism": http://ethics.unwto.org/en/content/accessible-tourism / (Accessed: 4/11/2016).

UNWTO (2016b), "World Tourism Day 2016 "Tourism for All - promoting universal accessibility" NEW! Good Practices in the Accessible Tourism Supply Chain: http://ethics.unwto.org/en/content/accessible-tourism/ (Accessed: 4/11/2016).

Vila, Domínguez., Darcy, Simon and. González, Alén E. (2015) "Competing for the disability tourism market-a comparative exploration of the factors of accessible tourism competitiveness in Spain and Australia”, Tourism Management, Vol. 47, PP. 261-72.

Visitbritain (2016), Destinations for All A guide to creating accessible destinations, https://www.visitbritain.org/sites/default/files/vb-corporate/dmo_guide_final.pdf, (accessed: 13/5/2017).

Wazzan, Wajdi (2015)," My Accessible Room is not Accessible, Applying Human Factors":Principals to Enhance the Accessibility of Hotel Rooms", Procedia Manufacturing, Vol. 3 , PP. 5405 - 5410.

Web Content Accessibility Guidelineshttps,( WCAG,)(2016)://www.w3.org/WAI/intro/wcag, (Accessed: 4/11/2016).

World Health Organization (WHO) (2011), "World report on disability", www.who.int/disabilities/world_report/2011/report.pdf/ (accessed: 13/1/2017).

Zhang, Ye and Cole, Shu (2016) "Dimensions of lodging guest satisfaction among guests with mobility challenges: A mixed-method analysis of web-based texts", Tourism Management, Volume 53, PP.13-27. 